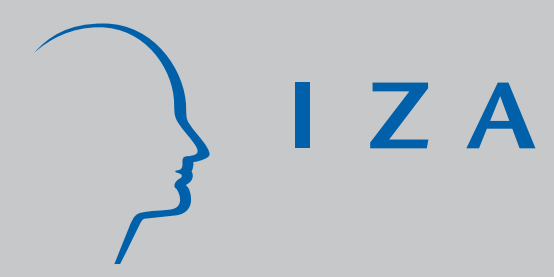

IZA DP No. 2090

Non-Pecuniary Returns to Higher Education:

The Effect on Smoking Intensity in the UK

Alfonso Miranda

Massimiliano Bratti

April 2006 


\section{Non-Pecuniary Returns to Higher Education: The Effect on Smoking Intensity in the UK}

Alfonso Miranda

University of Keele

Massimiliano Bratti

University of Milan

and IZA Bonn

Discussion Paper No. 2090

April 2006

IZA

P.O. Box 7240

53072 Bonn

Germany

Phone: +49-228-3894-0

Fax: +49-228-3894-180

Email: iza@iza.org

Any opinions expressed here are those of the author(s) and not those of the institute. Research disseminated by IZA may include views on policy, but the institute itself takes no institutional policy positions.

The Institute for the Study of Labor (IZA) in Bonn is a local and virtual international research center and a place of communication between science, politics and business. IZA is an independent nonprofit company supported by Deutsche Post World Net. The center is associated with the University of Bonn and offers a stimulating research environment through its research networks, research support, and visitors and doctoral programs. IZA engages in (i) original and internationally competitive research in all fields of labor economics, (ii) development of policy concepts, and (iii) dissemination of research results and concepts to the interested public.

IZA Discussion Papers often represent preliminary work and are circulated to encourage discussion. Citation of such a paper should account for its provisional character. A revised version may be available directly from the author. 


\section{ABSTRACT}

\section{Non-Pecuniary Returns to Higher Education: The Effect on Smoking Intensity in the UK ${ }^{*}$}

In this paper we investigate whether higher education (HE) produces non-pecuniary returns via a reduction in the consumption of health-damaging substances. In particular, the paper focuses on studying the smoking intensity of British individuals. We use data on current smokers from the 1970 British Cohort Study and estimate endogenous switching count models for cigarette consumption. Results show that HE is endogenous with smoking. Once endogeneity is controlled for, $\mathrm{HE}$ is found to have a higher negative effect on smoking than in models where it is treated as exogenous.

JEL Classification: C35, I12, I21

Keywords: endogenous switching, count data, higher education, smoking, UK

Corresponding author:

Massimiliano Bratti

Department of Economics, Business and Statistics

University of Milan

Via Conservatorio 7

I-20122 Milan

Italy

Email: Massimiliano.Bratti@unimi.it

\footnotetext{
"We acknowledge the original data depositor, the UK Data Archive (UKDA), which made available data from the 1970 British Cohort Study to us, and the original data collectors, the Department of Child Health at Bristol University and the Centre for Longitudinal Studies at the Institute of Education (University of London). Neither the original data collectors nor the data depositor bear any responsibility for the analyses or interpretations presented here. We are also grateful to Gauthier Lanot and Leslie Rosenthal for useful comments. The usual disclaimers apply.
} 


\section{Introduction}

Higher education (HE, hereafter) has been found to generate significant wage returns. In the case of the UK, for instance, Blundell et al. (2000) found that an undergraduate degree has, on average, 'raw' wage returns of around $21 \%$ for men and $39 \%$ for women in the National Child Development Study (NCDS). Similarly, Bratti et al. (2005) reported undergraduate degree returns of $14 \%$ for men and $18 \%$ for women from the 1970 British Cohort Study (BCS70).

Besides wage returns, there is a general agreement in the literature that education has important non-pecuniary returns (see, for instance, the survey in Wolfe and Haveman 2003). In the field of health, for example, education is thought to help individuals to avoid health damaging behaviour and to increase their life expectancy (Grossman 2005). Several papers have found important positive causal effects of education on health using instrumental variables (IV) techniques. ${ }^{1}$ However, only a few of them have investigated the pathways through which education produces health returns. One important pathway is that of the influence of education on health-related behaviour such as cigarette or alcohol consumption (see, for instance Farrell and Fuchs 1982, Sander 1995a;b). The present paper contributes a study on these issues for the case of the UK and focuses on a specific channel through which HE may affect health and life expectancy: the intensity of daily cigarette consumption. In particular, the variable of interest is the number of cigarettes daily smoked, given current participation in the smoking activity?

There are at least two current policy reasons motivating our study. First, there is the fact that the UK has undergone a gradual transition towards a quasi-market in the HE sector. As a consequence, university student tuition fees are being progressively increased to reflect properly the large private returns that graduates from HE obtain in terms of both wages and a higher

\footnotetext{
${ }^{1}$ See, for instance, Berger and Leigh (1989), Adams (2002), Lleras-Muney (2005) and Arendt (2005).

${ }^{2}$ Also Clark and Etilé (2002) study smoking intensity in the UK, but their main focus is not on education, which is considered as exogenous.
} 
probability of employment. From this perspective, individuals who pay for HE studies are naturally interested in learning whether their investment has unaccounted non-pecuniary returns such as general improvements in health. Second, the existence of important health returns to HE implies that an increased access to HE may help to improve the health condition of the average UK citizen and decrease expenditures in public health. Hence, the government may be interested in internalising such benefits when deciding the amount of public funds to be allocated to support HE activities.

Evaluating non-pecuniary returns to HE is substantially complicated by the fact that HE is potentially endogenous with smoking behaviour. Such endogeneity arises whenever unobserved individual characteristics affecting the likelihood to get a HE degree are correlated with unobserved heterogeneity determining smoking decisions. The rate of time preference is an example of such unobserved characteristics that is often emphasised in the literature. On the one hand, it is argued that individuals who heavily discount the future are more likely to engage in health damaging activities such as smoking. On the other hand, impatient individuals heavily discount future incomes and are therefore less likely to invest in human capital (see, for instance, Fersterer and Winter-Ebmer 2003). Hence, if education is taken as exogenous in a smoking equation, estimates may be subject to a substantial bias.

Most previous work that investigate the effect of education in smoking typically use data from the USA and study the determinants of smoking status (i.e., activity participation) rather than the determinants of intensity of substance use. For these reasons, binary health responses (smoking vs. non-smoking) are analysed and the endogeneity of education - usually taken to be a continuous variable - is controlled for by instrumental variable

\footnotetext{
${ }^{3}$ Another strand of the literature on smoking is concerned with tobacco expenditure. These studies have the disadvantage of modelling a variable that fluctuates due to price changes and that, as a consequence, introduces uninformative noise to the two relevant dimensions of analysis: (a) participation status, and (b) intensity of substance use. The expenditure approach has also the disadvantage of artificially imposing a continuous variable framework to a problem that is necessarily generated by discrete data generating mechanisms. Double-Hurdle models are commonly used in this literature (for further reference see, among others, Cragg 1971, Labeaga 1999).
} 
techniques (see, for instance, Sander 1995a;b). Following the general trend, research in the UK commonly aims to understand the determinants of smoking status. However, unlike the USA, available literature for the UK typically takes education as an exogenous variable (see, among others, Chandola and Bartley 2004, Forster and Jones 2003). To our knowledge, the only article studying smoking behaviour in the UK that treats education as endogenous is that of Chandola et al. (2006). The authors use the National Child Development Study (NCDS) — which collects data on the 1958 British Cohort and find a strong negative effect of education on the probability of being a non-smoker. Our analysis differs from that of Chandola et al. (2006) as we consider a more recent British cohort, born in 1970, and focus on the effect of HE on smoking intensity rather than on smoking status.

The present paper explicitly recognises the non-negative and integer nature of the data. For these reasons count data techniques are used for the analysis. Moreover, the potential endogeneity of the HE dummy is explicitly addressed by using an endogenous switching framework. Among other advantages, the endogenous dummy variable strategy enables the researcher to control properly for the presence of unobserved heterogeneity in both the count outcome and the switching equation. Besides, unlike popular IV procedures, the endogenous switching model delivers directly correct standard errors. This is major advantage since other studies fail to obtain statistically significant effects of education when using a two-stage IV approach, probably due to weak instruments (see, for instance, Arendt 2005, on the effect of education on health).

Our study benefits from a unique longitudinal data set, the 1970 British Cohort Study (BCS70, hereafter), that follows the same individuals at birth and ages 5, 10, 16, 26 and 30. These data are rich in background information on the sampled individuals and offer a number of potential instruments for the endogenous HE dummy.

The structure of the paper is as follows. Section 2 mainly outlines the reasons for which a negative correlation between $\mathrm{HE}$ and smoking might 
emerge, some of which reflect causal effects, and reports a brief survey of the previous literature. Section 3 briefly describes our estimation sample. Section 4 introduces the endogenous switching count model that is used for the analysis. Finally, section 5 reports the main empirical results and the last section concludes.

\section{Does education affect smoking? Why?}

The literature has emphasised several possible sources of correlation between education and health, some of which reflect causal pathways.

The third variable hypothesis suggests that education is endogenous in a smoking equation because education and smoking decisions are likely to be affected by the same set of unobserved factors (Fuchs 1982). To clarify this point consider the case of the intertemporal discount rate. On the one hand, individuals with a high discount rate are likely to invest less in education and consume more cigarettes. On the other hand, individuals with a low discount rate are likely to stay longer in education and use more effectively information about the harmful effects of smoking on health and life expectancy. Hence, from the third variable hypothesis perspective, a negative correlation between education and smoking stems from a third variable and does not reflect a causal relationship (see, for instance Farrell and Fuchs 1982, Sander 1998).

Grossman (1972) stressed the productive efficiency argument. The underlying idea is that education directly affects the health production function, and that, given the same quantity of inputs, educated individuals produce a higher stock of health than uneducated individuals. Empirical investigation of this hypothesis usually involves the estimation of a health production function. The stock of health capital is measured by self-rated health variables and education is included in the right-hand-side (RHS, hereafter) along other controls. Evidence supporting the productive efficiency hypothesis is obtained if the coefficient on education is statistically different from zero. Since in the current paper we analyse decisions regarding smoking intensity 
— i.e., an input into the health production function — we do not develop further on this argument and the interested reader can refer to Grossman (2005) for a recent survey on the topic.

According to the allocative efficiency argument, education alters the input mix in the health production function. As Rosenzweig and Schultz (1983) put forward, this argument in its strongest form maintains that education has no impact on health unless it changes inputs in the health production function, and the coefficient on education in this function would be zero if all inputs were included. Hence, the main mechanism through which education affects the input mix is by increasing health related knowledge - e.g. on the harmful effects of smoking, or the speed of adoption of health enhancing inputs. However, the evidence supporting this argument is mixed. ${ }^{4}$ In our sample almost all individuals were informed about the damaging effects of smoking already at age 10, and therefore later education and particularly HE is unlikely to have had a substantial impact on improving health knowledge related to smoking. ${ }^{5}$

Other hypotheses may be put forward. One may, for instance, argue that rational utility-maximising individuals take into account both current and future health consequences of their current smoking decisions. In this context, educated workers who earn higher wages have higher economic returns to good health than uneducated workers. As a consequence, higher earners are more likely to refrain from current smoking. Using a similar argument one may say that young individuals who invest in education will avoid smoking even before completing education because such behaviour reduces future loss of work days and increases their life expectancy. This can provide an alternative explanation for the evidence in Farrell and Fuchs (1982) suggesting that educated individuals smoke less even before completing education, which

\footnotetext{
${ }^{4}$ Studies finding evidence in favour of this explanation of the effect of education include De Walque (2004) while evidence in Kenkel (1991) and Nerín et al. (2004) does not support this argument.

${ }^{5}$ In particular, $77.29 \%$ of our sample declared that they were sure that smoking can damage health, $7.31 \%$ were not sure while $0.99 \%$ declared that they were sure that smoking does not damage health (the remaining individuals did not answer).
} 
the authors interpret as evidence supporting the third variable hypothesis. There might be other channels through which education has a causal effect on smoking behaviour. Examples include the positive effect of education on self-control (see Ross and Mirowsky 1999), and the effect of education on a person's time discount rate (Becker and Mulligan 1997).

Besides education, the literature has emphasised other important covariates/determinants of individual smoking decisions. For instance, Powell et al. (2005) find strong peer effects in youth smoking decisions. Moreover, the authors find that the smoking status of the members of an individual's peergroup are exogenous with respect to her own smoking decisions. Finally, education of parents had an insignificant effect on smoking, and communication between parents and children reduced the odds of entering the smoking activity.

Bantle and Haisken-DeNew (2002) emphasised the intergenerational links in smoking behaviour. There are several reasons why there might be intergenerational transmission in smoking behaviour. Parents act as role models for children and children may infer from parents' smoking that they can derive utility from cigarettes or that the benefits from smoking exceed its harmful effects. However, parents might also attempt to impose smoking bans on their children and if the parents themselves are smokers they might not be credible. The authors included several potential determinants of both parents' and children's smoking behaviours such as parents' highest education, household size, income and income per capita and did not find a significant effect of these factors over and above the positive effect of parents' smoking on children's smoking. Similar results are found by Emery et al. (2001) who observed an insignificant effect of parental education and incomes on smoking behaviour of individuals aged 14 or more, while finding a strong positive effect of exposure to smoking within the family. Blow et al. (2005) investigated the effect of parental income on children's smoking behaviour using British Household Panel Survey (BHPS) data and found no effect of parental income when including a dummy for the presence of an adult smoker in the 
family and a significant positive effect on children's smoking only of mothers with no formal education. Their conclusion is that "a large part of the relationship between children's smoking behaviour and parental socio-economic status is transmitted via the smoking status of the adults" (p. 10). ${ }^{6}$

\section{Data}

In this paper we use data drawn from the BCS70. The BCS70 began in 1970 when data were collected on the births and families of 17,198 babies born in England, Wales, Scotland and Northern Ireland from the $5^{\text {th }}$ to the $11^{\text {th }}$ of April. ${ }^{7}$ There are currently five complete follow-up surveys available: 5-year, 10-year, 16-year, 26-year and 30-year. As to the variables included in our empirical analysis, data on smoking habits and the highest educational qualification were collected in the 30-year follow-up survey while all the other contextual variables used in the econometric analysis were provided in the 10-year follow-up survey. We use, therefore, a sample of individuals who were present in the two waves. The BCS70 was affected by same panel attrition. Although nothing ensures that panel attrition is at random with respect to the variables representing the main focus of our paper, i.e. education and smoking, previous work (see, e.g., Bratti et al. 2005) noted that individuals in the matched samples generally have very similar observable characteristics to those in the initial waves and that therefore attrition across waves should not affect the individual characteristics which we are interested in. ${ }^{8}$

In the age 30 follow-up there is some information on smoking behaviour. In particular, the relevant questions are:

\footnotetext{
${ }^{6}$ An insignificant effect of father's education on a child's smoking is also found in Farrell and Fuchs (1982).

${ }^{7}$ Subjects from Northern Ireland were included in the birth survey, but have been excluded from all subsequent sweeps.

${ }^{8}$ The Office for National Statistics (1999) writes "Analysis of differential response comparing achieved samples and target samples for any follow-up, using data gathered during the birth and earlier follow-ups, show that the achieved sample are broadly representative of the target sample. However, as in other surveys, some groups (eg those from minority ethnic, low social class, and atypical family backgrounds) are under-represented" (p. 11).
} 
would you say that: (a) you've never smoked cigarettes; (b) you used to smoke cigarettes but not at all now; (c) you now smoke cigarettes occasionally but not every day; (d) you smoke cigarettes every day?

and

how many cigarettes a day do you usually smoke?

The distribution of valid answers to the first question is shown in Table 1. About $29 \%$ of individuals in our sample smoke cigarettes every day, while $7.7 \%$ smoke occasionally. Every-day smokers are asked the number of cigarettes smoked a day (i.e. the second question). In the present paper we consider all current smokers and set the number of cigarettes smoked a day at zero for occasional smokers.

\section{[Table 1 about here]}

Self-reported data on daily cigarette consumption may contain errors. In particular, when looking at the distribution of the number of cigarettes smoked daily (see Figure 1) in our sample we observe that fractions and multiples of a packet are more likely to occur. This is not a distinctive feature of our sample but a common phenomenon found in studies of cigarette consumption (see, for instance Clark and Etilé 2002, who use BHPS data). ${ }^{9}$

[Figure 1 about here]

\footnotetext{
${ }^{9}$ In general, it is hard to say in what measure the peculiar pattern observed for cigarette consumption reflects a true pattern or is affected by measurement error. Our personal view is that current smokers, when reporting the number of cigarettes smoked a day, may approximate it to the closest multiple of five, and, as the distribution suggests, this is more likely to happen when consumption is high. We think that although this may cause some bias to our estimates, it does not change our main qualitative and quantitative results. We decided not to use an ordered Probit model because there are far too many mass points to be fitted and estimating a model for the number of packets, in opposition to the number of cigarettes, would have implied the loose of important variation at the tails of the distribution shown in Figure 1.
} 
Table 2 reports the average number of cigarettes smoked a day by level of education. HE refers to individuals with a degree level qualification or more. In particular, $\mathrm{HE}$ includes individuals with levels of qualification 4 or 5 in the standard UK classification of educational qualifications (see, for instance, Bynner et al. 2002, p. 45). Male smokers with HE smoke about four less cigarettes a day than those with less than HE (-41\%). The difference in the number of cigarettes smoked a day between female smokers with HE and those with less than HE is similar and amounts to almost four cigarettes $(-48 \%)$.

[Table 2 about here]

In this paper we will compare daily cigarette consumption of individuals with $\mathrm{HE}$ with those with lower educational qualifications. Hence, the "treatment" is having HE and the control group is represented by individuals with lower levels of education. The composition of the control group (lower than HE) by highest educational qualification achieved is reported in Table 3. Table 3 clearly shows that the control group is mostly composed of individuals who did not go on in post-compulsory schooling (79\% for males and $85 \%$ for females). Hence, the effect of HE that we will estimate can be roughly interpreted as the effect with respect to individuals with no more than compulsory education.

[Table 3 about here]

\section{Econometric methodology}

Endogenous switching models for count variables are used for our empirical analysis (see, for instance, Terza 1998, Kenkel and Terza 2001, Miranda and Rabe-Hesketh 2005). Denote by $y_{i}$ the number of cigarettes diary consumed by the $i-t h$ individual. By assumption $y_{i}$ takes on non-negative integer values and is a function of a potentially endogenous dummy, $E_{i}$, and a $K \times 1$ vector of individual characteristics $\mathbf{x}_{\mathbf{i}}$ - including the constant term. In the 
present context $E_{i}$ represents an indicator for successful completion of a $\mathrm{HE}$ degree. We suppose that $y$ is distributed as a Poisson variate,

$$
\operatorname{Pr}\left(y_{i} ; \mathbf{x}_{\mathbf{i}}, E_{i}, u_{i}\right)=\frac{\exp \left[\mathbf{x}_{\mathbf{i}}^{\prime} \boldsymbol{\beta}+\theta E_{i}+u_{i}\right]^{y_{i}} \exp \left\{-\exp \left[\mathbf{x}_{\mathbf{i}}^{\prime} \boldsymbol{\beta}+\theta E_{i}+u_{i}\right]\right\}}{y_{i} !},
$$

where $u_{i}$ is an unobserved individual heterogeneity term. As usual, the endogenous dummy is modelled as a latent response,

$$
\begin{aligned}
& E_{i}^{*}=\mathbf{z}_{i}^{\prime} \gamma+v_{i} \\
& E_{i}= \begin{cases}1 & \text { if } S_{i}^{*}>0 \\
0 & \text { otherwise }\end{cases}
\end{aligned}
$$

with $\mathbf{z}_{i}$ representing a $L \times 1$ vector of explanatory variables (including the constant), $\gamma$ the vector of associated coefficients, and $v_{i}$ a random variate. The model is technically identified by functional form (Kenkel and Terza 2001). As a consequence, vectors $\mathbf{x}_{i}$ and $\mathbf{z}_{i}$ may contain some or all common elements.

The main objective of the researcher is to obtain consistent estimators of the $K \times 1$ vector of parameters $\boldsymbol{\beta}$ and the coefficient on $E_{i}, \theta \in \mathbb{R}$. Matters are essentially complicated by the fact that $u_{i}$ and $v_{i}$ may be correlated, leading to a classic problem of endogeneity of $E_{i}$ in equation (1). Clearly, in such a case estimation of equation (1) under the assumption of exogenous education will deliver biased and inconsistent estimators. To avoid this problem the relationship between $u_{i}$ and $v_{i}$ must be explicitly modelled and equations (1) and (2) should be estimated as a system.

The standard approach to allow correlation between $u_{i}$ and $v_{i}$ is to assume that the two random terms are jointly normally distributed (see Terza 1998). Here we follow the same tradition. However, for simplicity, direct dependence between $u_{i}$ and $v_{i}$ is induced. Namely, we suppose that

$$
v_{i}=\lambda u_{i}+\zeta_{i}
$$


with $u_{i}$ and $\zeta_{i}$ distributed as independent normal variates with 0 mean. The $\lambda \in \mathbb{R}$ term in equation (3) represents a 'factor loading' that is estimated along the other parameters of the model.

Given that the variance in a Probit is only identified up to a constant, we set $\operatorname{Var}\left(\zeta_{i}\right)$ to 1 without loss of generality. In the case of $u_{i}$ there is no need to impose any restriction on $\sigma^{2}=\operatorname{Var}\left(u_{i}\right)$ because the Poisson distribution in this model can accommodate overdispersion (see below). Under the structure imposed by equation (3) the covariance matrix of $u_{i}$ and $v_{i}$ is given by:

$$
\operatorname{Cov}\left[\left(u_{i}, v_{i}\right)^{\prime}\right] \equiv \Sigma=\left[\begin{array}{cc}
\sigma^{2} & \lambda \sigma^{2} \\
\lambda \sigma^{2} & \lambda^{2} \sigma^{2}+1
\end{array}\right],
$$

and the correlation is

$$
\rho=\frac{\lambda \sigma^{2}}{\sqrt{\sigma^{2}\left(\lambda^{2} \sigma^{2}+1\right)}} .
$$

Equations (1) through (3) define a reparametrisation of the model introduced by Terza (1998). In Terza's model, however, the variance of $v_{i}$ is set to 1 while the total variance of $v_{i}$ is $\left(\lambda^{2} \sigma^{2}+1\right)$ here. Hence, it is possible to recover Terza's parameterisation by dividing our estimates for the switching equation by $\sqrt{\lambda^{2} \sigma^{2}+1}$.

The model is estimated by maximum likelihood and at convergence the negative of the inverse of the Hessian matrix can be used as an estimator for the covariance matrix. Robust standard errors can be obtained in the usual way. To evaluate the likelihood function, the random term $u_{i}$ must be integrated out. Gauss-Hermite quadrature may be used to perform this task. Here, however, we use adaptive quadrature (Rabe-Hesketh and Skrondal 2002). Adaptive quadrature is a numerical integration technique that, at each iteration, updates the location and weights of the Gauss-Hermite quadrature points using the posterior distribution of $u_{i}$. After update, locations are centred around the posterior mean and equally spread out according to the posterior standard deviation. Adaptive quadrature has proven to achieve higher accuracy with fewer integration points than the ordinary Gauss-Hermite quadrature. 
One should be aware that a model with exogenous switching (EXS) is nested within the endogenous switching (ES) framework. This is so because if $\rho=0$ the random terms $u_{i}$ and $v_{i}$ are independent and the likelihoods for the count and the dummy variables are separable - which is what is actually meant by exogenous switching in the econometrics literature (see Winkelmann 1998). This implies then that a test for the endogeneity of $E_{i}$ in equation (1) can be performed on the basis of a simple likelihood ratio test for $\rho=0$.

A final remark about the ES Poisson model is necessary. Namely, that despite a Poisson distribution imposes the equality of mean and variance (known as the equidispersion property of the Poisson distribution) the model defined in equation (1) does not necessarily imply that, given the covariates, the conditional mean of $y$ is equal to its conditional variance. In fact, it is easy to show that

$$
\operatorname{Var}\left[y_{i} \mid \mathbf{x}_{i}, E_{i}\right]=\mu_{i}+k \mu_{i}^{2}
$$

where $\mu_{i}=E\left[y_{i} \mid \mathbf{x}_{i}, E_{i}\right]$ and $k=\left(\exp \left(\sigma^{2}\right)-1\right)$. Variable $y$ will therefore exhibit overdispersion as long as $\sigma^{2} \neq 0$. Notice, furthermore, that $\sigma^{2}$ may be statistically different from zero even in the case that a $\rho=0$ is found. Hence, unobserved heterogeneity may be present — and controlled for even if the higher education dummy, $E_{i}$, turns out to be exogenous in the smoking equation.

We will use the evidence from the previous literature to propose some candidate instrumental variables to identify the effect of higher education on smoking. In the light of the findings reported in section 2 one can reasonably assume that the main influence of a parent's education on his/her children smoking amounts to the transmission of health knowledge, differences in parenting styles, and the role model transmitted through his/her own smoking habits. As a consequence, a parent's education should affect smoking behaviour only through its effect on children's education once health awareness and parental smoking status are controlled for. ${ }^{10}$ Following this argument we

\footnotetext{
${ }^{10}$ We use parents' interest in a child's education at age 10 as proxies of parenting styles.
} 
exclude parental education from the smoking equation. ${ }^{11}$ Clearly, imposing this restriction delivers an additional instrument for identifying the effect of HE. The effect of parental education on a child's education is already well established in the literature (see for instance Ermisch and Francesconi 2001, Chevalier and Lanot 2002, for some UK related evidence). The strength of these instruments was in any case tested by performing formal Wald tests for the exclusion of parental education variables from the smoking and higher education equations in the ES poisson model including parents' education in both equations.

On the grounds of the literature review in section 2, our econometric model will enable us to distinguish among some alternative hypotheses on the effect of HE on smoking. In particular, we will be able to distinguish among these four different situations: 1) the correlation coefficient $\rho$ is not statistically different from zero and the coefficient on HE in the smoking equation is statistically significant. In this case $\mathrm{HE}$ is exogenous with respect to smoking behaviour and its effect is causal; 2) the correlation coefficient $\rho$ is statistically significant while the coefficient on HE in the smoking equation is not. In this case $\mathrm{HE}$ is endogenous and the correlation between $\mathrm{HE}$ and smoking behaviour is driven by unobserved heterogeneity: it is the so-called "third variable hypothesis" emphasised by Farrell and Fuchs (1982); 3) both the correlation coefficient $\rho$ and the coefficient on HE in the smoking equation are significant. In this case although HE is endogenous with smoking, it also has a causal impact on smoking behaviour. The estimates of $\rho$ and of the causal effect of HE will also give an idea of the relative importance of the two alternative explanations, i.e. "third variable hypothesis" vs. causal effects; 4) the correlation coefficient and the coefficient on HE in the smoking equation are both insignificant. In this case our analysis will not support any of the hypotheses outlined in the literature review.

Like most of the previous literature based on IV, our analysis will only

\footnotetext{
${ }^{11}$ The same identifying restriction is used, for instance, by Sander (1995a;b) to estimate the causal effect of education on smoking status.
} 
shed light on the presence of causal effects of education on smoking behaviour while we will not able to distinguish among the different pathways through which this influence takes place. As we have said, different channels could be involved, such as those based on health-related information, endogenous time preference or the economic returns to health. It should also be noted that by excluding from the RHS of the smoking equation current or past jobrelated variables - such as qualification, sector or income that are likely to be affected by education - our study is necessarily constrained to estimate the "total effect" of education on smoking. ${ }^{12}$

\section{Empirical Results}

We start our empirical analysis by estimating count models treating the HE dummy as exogenous. Since these models represent a benchmark for our later analysis we include all the variables that we use in the ES model and that are selected using Wald tests. ${ }^{13}$ Given the model specification in section 4 an incidence rate (IR) is defined as:

$$
I R=\exp \left(\mathbf{x}_{\mathbf{i}}^{\prime} \boldsymbol{\beta}+\theta E_{i}\right)
$$

The IR is the rate at which an event occurs, and in our case can be roughly interpreted as the "speed" at which smoking takes place in the unit of time, i.e. a day in our case. IRs multiplied by the time of exposure (e.g., number of days) gives the number of occurrences of smoking in the period of interest,

\footnotetext{
${ }^{12}$ We consider education as the main determinant of occupation, sector of employment, and income. These potentially endogenous variables were excluded from the present study to keep the addressed problem tractable. Hence, a reduced-form model is estimated here. Going further, estimation of a structural model requires the specification of a number of extra equations — one for each additional endogenous variable. In that context, correlation among unobservables across all equations should be freely allowed. Beyond the obvious modelling complexities, following such an strategy demands a set of additional instruments to secure identification of the structural model. The BCS70 contains no sufficient instruments to estimate such a complex system.

${ }^{13}$ The Wald tests are available upon request from the authors. We selected regressors by estimating the smoking and HE equations separately and keeping only statistically significant regressors at $10 \%$ level or more.
} 
in our case the number of cigarettes smoked. Differences in rates of smoking between two individuals $i$ and $j$ with different characteristics can be evaluated using Incidence Rate Ratios (IRR) that are defined as:

$$
I R R=\frac{\exp \left(\mathbf{x}_{\mathbf{i}}^{\prime} \boldsymbol{\beta}+\theta E_{i}\right)}{\exp \left(\mathbf{x}_{\mathbf{j}}^{\prime} \boldsymbol{\beta}+\theta E_{j}\right)} .
$$

If two individuals have the same characteristics and, therefore, smoke at the same speed, the IRR equals one. Hence, a way to evaluate the effect of individual characteristics on smoking is to compute their impact on IRRs. In the case of a dichotomic characteristic, such as the dummy for higher education $E_{i}$, the effect on smoking for a generic individual $i$ can be evaluated by comparing the change in the IRR produced by $E_{i}$ :

$$
\Delta I R R\left(E_{i}\right)=\frac{\exp \left(\mathbf{x}_{\mathbf{i}}^{\prime} \boldsymbol{\beta}+\theta\right)}{\exp \left(\mathbf{x}_{\mathbf{i}}^{\prime} \boldsymbol{\beta}\right)}-\frac{\exp \left(\mathbf{x}_{\mathbf{i}}^{\prime} \boldsymbol{\beta}\right)}{\exp \left(\mathbf{x}_{\mathbf{i}}^{\prime} \boldsymbol{\beta}\right)}=\exp (\boldsymbol{\theta})-1 .
$$

In the case of continuous variables we computed the effect determined by a one-unit increase in the value of the variables. Robust standard errors for the IRRs can be calculated using the delta method and a robust estimator of the covariance matrix of the original coefficients.

We estimated two models, the first one is a simple Poisson model and the second one is a Poisson model with unobserved heterogeneity (see section 4 , it is the smoking equation in the ES model with $\rho=0$ ). We estimated separate gender-specific models because, as, in principle, factors affecting smoking behaviour may differ by gender.

The estimates from the simple Poisson models reported in Tables 4 and 5 show that HE is significantly associated with a reduction in smoking rates both for males and females. The estimated effects are very similar for both genders. The change in the IRR is -0.246 for females and -0.247 for males, i.e. females with HE smoke $24.7 \%$ less cigarettes a day than those with lower education, while the equivalent effect is $24.8 \%$ for males.

The simple Poisson model is based on the restrictive assumption that the mean of the distribution is equal to its variance and cannot account for overdispersion. Therefore, a first generalisation of the poisson model can be 
obtained by introducing log-normal unobserved heterogeneity. As we already said in section 4, unobserved heterogeneity can be present and controlled for even in the case where HE is restricted to be exogenous. Tables 4 and 5 show that if unobserved heterogeneity is controlled for the negative effect of HE on the IRRs remains highly significant for both males and females. More importantly, results suggest that men (women) with a HE degree smoke $39 \%$ (40\%) less than those with lower educational qualifications. Hence, the Poisson model with log-normal heterogeneity suggests that the effect of $\mathrm{HE}$ on smoking is much larger than a simple Poisson would suggest.

The endogenous switching model is formally identified through functional form. However, in order to have also an "economic identification" at least one variable affecting $\mathrm{HE}$ must be excluded from the smoking equation. The covariates to be included in the $\mathrm{HE}$ and in the smoking equations were selected estimating the two equations separately, performing Wald tests, and excluding all variables not significant at the $10 \%$ level. Hence, in general, the model is identified by more than one exclusion restriction. We consider parents' highest educational qualifications, nonetheless, to be the main identifying variables.

[Table 4 about here]

Table 4 reports the ES results for the females using parents' education as the main exclusion restrictions. The coefficients on parents' educational qualifications show that they are strong predictors of their children's levels of education (see Table 6 in Appendix). For instance, women whose mothers have a university degree are 38.52 percentage points more likely to get a $\mathrm{HE}$ with respect to those whose mothers have less than O-level education. Similarly, women whose fathers have HE are 17.1 percentage points more likely to obtain HE. The Wald tests for parents' education exclusion reported at the bottom of Table 4 show that parents' education can be excluded from the smoking equation but it cannot be excluded from the HE equation. There are other factors that are significantly correlated with HE such as mother's 
interest in a child's education (assessed at age 10) and the British Ability Scales score. ${ }^{14}$

Once the endogeneity status of $\mathrm{HE}$ is controlled for results show that women with HE consume $56.1 \%$ less cigarettes than those with lower education. Similar results are obtained for males. In fact, it is estimated that HE reduces men's daily cigarette consumption by $60.7 \%$ (see Table 5). Clearly, in both cases results show that the effect of $\mathrm{HE}$ on smoking is much higher in ES models than in models that treat $\mathrm{HE}$ as an exogenous variable.

\section{[Table 5 about here]}

The ES models reported in Tables 5 and 4 show a significant positive correlation between unobservables in the $\mathrm{HE}$ and smoking equations - i.e., a positive and significant $\rho$ - for both males and females. Since it is hard to say what is generating this correlation, we can only provide here some speculative answers.

Economic literature has emphasised two main reasons for finding a negative, rather than a positive, correlation between the unobservables affecting education and smoking. A first example is unobserved ability. Ability affects a child's likelihood to go on in HE and for several reasons it can affect smoking, for instance, by increasing the amount of medical information to which an individual has access or by increasing an individual's labour income and consequently the potential loss due to diseases. A second example is an individual's discount rate. Individuals with high discount rates are likely to invest less in education and engage in health-damaging behaviour, such as smoking.

It must be noted, however, that a positive $\rho$ cannot be excluded on theoretical grounds. Notice that in the HE equation we control for a proxy

\footnotetext{
${ }^{14}$ Parents' characteristics affecting HE sometimes differ between genders. We do not find this evidence particularly surprising. Indeed, the influence of parents on children's outcomes may differ according to gender as parents may act as role models. Chevalier (2004), for instance, finds a stronger influence of same-sex parents on children's educational achievements.
} 
of ability (the British Ability Scales score ${ }^{15}$ ). Further, some other family background covariates may actually proxy the discount rate. Hence, the "classic" negative correlation between smoking and HE might be already accounted for by the included explanatory variables. Moreover, the role of the discount rate and innate ability may be more important in determining smoking status than smoking intensity (conditional on current smoking). In this context, the positive $\rho$ can be associated to the exclusion of other relevant variables. An example is an individual's health stock — often called "frailty" in biomedicine. Clearly, healthy individuals are likely to invest more in education and to achieve better educational results than unhealthy individuals. At the same time, healthy individuals can smoke more without compromising their health. Evidence consistent with this interpretation is provided, for instance, in Clark and Etilé (2002) who found that past improvements in health while smoking are positively correlated with current cigarette consumption. ${ }^{16}$ Other explanations may also be possible. For instance, higher earning ability may increase the demand for cigarettes and education via an income effect.

\section{Concluding remarks}

The present paper uses endogenous switching count models to estimate the effect of higher education (HE) on smoking intensity in the UK - i.e., number of cigarettes consumed daily, given current participation on the smoking activity. Data for current smokers from the 1970 British Cohort are analysed. The main findings are as follows:

- HE is found to be endogenous with respect to smoking.

\footnotetext{
${ }^{15}$ See Elliot and Pearson (1979).

${ }^{16}$ Although the BCS70 gathers information on an individual's current perceptions of their health status, we do not include it in the smoking equation since it is likely to be endogenous with an individual's education, which may increase an individual's "health stock".
} 
- Empirical evidence suggests that the effect of HE on smoking is much more substantive than models with exogenous education would predict. Indeed, after controlling for endogeneity, it is found that HE reduces daily cigarette consumption by $56 \%$ for women and by $61 \%$ for men. In contrast, if endogeneity is neglected, HE reduces cigarette consumption only by $40 \%$ and $39 \%$ for women and men respectively.

- Unlike what is reported in previous literature, we found a statistically significant positive correlation between the unobserved heterogeneity that enter the smoking and the higher education equations. Previous work has mostly emphasised unobservable variables that are likely to induce a negative correlation. The leading examples are the subjective intertemporal rate discount rate or innate ability. We argue that in the present analysis these effects are partly captured by some of the control variables included in the model, such as social class or the British Ability Scales score. A tentative explanation that we put forward for the observed positive correlation is that an individual's unobserved 'health stock' is likely to positively affect both his/her educational attainment and his/her cigarette consumption, since healthier individuals can smoke at higher rates being less at risk of compromising their health. Evidence consistent with this interpretation is found also by Clark and Etilé (2002).

We believe that the findings of the present paper show the existence of important 'health returns' to HE in the UK. Such evidence may be important to inform the current debate on the funding of HE in the UK. Indeed, although the recent increase in student fees and in the incidence of private funding of the HE system have been motivated by the high private economic returns to HE, our analysis shows important non-pecuniary returns to HE. If these 'health returns' are not considered by individuals who plan to invest in $\mathrm{HE}$, the amount of education chosen could be lower than the optimal level. Moreover, these 'health returns' are likely to produce a positive externality for the collectivity as a healthier population also means important savings in 
public health expenditures. Therefore, the optimal amount of public funding to HE should be determined also considering these non-pecuniary returns. 


\section{Tables and Figures}

Table 1. Smoking habits in the 30-year follow-up of BCS70

\begin{tabular}{lccc}
\hline Smoking habits & Frequency & Percent & Cumulate \\
\hline never smoked cigarettes & 4,937 & 44.06 & 44.1 \\
used to smoke but don't at all now & 2,125 & 18.97 & 63 \\
smoke cigarettes occasionally & 863 & 7.7 & 70.7 \\
smoke cigarettes every day & 3,279 & 29.27 & 100 \\
\hline Total & 11,204 & 100 & \\
\hline
\end{tabular}

Note. The distribution refers to valid answers only.

Table 2. Number of cigarettes smoked daily by education (current smokers)

\begin{tabular}{lccccccc}
\hline & \multicolumn{3}{c}{ Males } & & \multicolumn{3}{c}{ Females } \\
\cline { 2 - 3 } Education at age 30 & Mean & Std. Dev. & Freq. & & Mean & Std. Dev. & Freq. \\
\hline lower than HE & 13.45 & 9.45 & 1529 & & 11.37 & 7.94 & 1350 \\
HE & 9.53 & 8.89 & 461 & & 7.68 & 7.80 & 408 \\
\hline Total & 12.54 & 9.47 & 1990 & & 10.51 & 8.06 & 1758 \\
\hline
\end{tabular}

Table 3. Highest educational qualification of the lower than HE group

\begin{tabular}{lrrrrrrrrr}
\hline & \multicolumn{3}{c}{ Males } & & \multicolumn{3}{c}{ Females } \\
\cline { 2 - 3 } \cline { 8 - 10 } Composition & Freq. & Percent & Cum. & & Freq. & Percent & Cum. \\
\hline No formal qualification & 350 & 23.01 & 23.01 & & 336 & 24.96 & 24.96 \\
Level 1: GSCE D-G, CSE 2-5,.. & 180 & 11.83 & 34.85 & & 167 & 12.41 & 37.37 \\
Level 2: O-level equiv. & 667 & 43.85 & 78.7 & & 639 & 47.47 & 84.84 \\
Level 3: A-level equiv. & 324 & 21.3 & 100 & & 204 & 15.16 & 100 \\
\hline Total & 1,521 & 100 & & & 1,346 & 100 & \\
\hline
\end{tabular}

Note. Level 1 and Level 2 refer to compulsory schooling while Level 3 to post-compulsory schooling. 
Table 4. Effect of explanatory variables on the IRR of smoking - Women

\begin{tabular}{|c|c|c|c|c|}
\hline \multirow[b]{2}{*}{ Variable } & \multirow{2}{*}{$\begin{array}{c}\text { Poisson } \\
\Delta \text { IRR }[\mathrm{RSE}] \\
\end{array}$} & \multirow{2}{*}{$\begin{array}{l}\text { Poisson }+ \text { unobs. Het. } \\
\Delta \text { IRR }[\text { RSE }]\end{array}$} & \multirow{2}{*}{$\begin{array}{r}\text { ES Poisson } \\
\Delta \mathrm{IRR}[\mathrm{RSE}] \\
\end{array}$} & \multirow[t]{2}{*}{ mean } \\
\hline & & & & \\
\hline \multicolumn{5}{|l|}{ Education at age 30} \\
\hline $\mathrm{HE}$ & $-0.246[0.040]^{* * *}$ & $-0.402[0.051]^{* * *}$ & $-0.561[0.084]^{* * *}$ & 0.233 \\
\hline \multicolumn{5}{|l|}{ Parents } \\
\hline no mother & $0.368[0.246]$ & $0.558[0.449]$ & $0.502[0.428]$ & 0.007 \\
\hline no father & $0.055[0.116]$ & $0.085[0.159]$ & $0.071[0.161]$ & 0.080 \\
\hline \multicolumn{5}{|l|}{ Friends smoke } \\
\hline some of them & $-0.026[0.108]$ & $-0.107[0.149]$ & $-0.089[0.153]$ & 0.113 \\
\hline none of them & $-0.190[0.084]^{* *}$ & $-0.297[0.108]^{* * *}$ & $-0.281[0.111]^{* *}$ & 0.732 \\
\hline missing info. & $-0.183[0.112]$ & $-0.304[0.149]^{* *}$ & $-0.288[0.153]^{*}$ & 0.137 \\
\hline \multicolumn{5}{|c|}{ Mother interested in child's education } \\
\hline little interest & $0.120[0.062]^{*}$ & $0.165[0.106]$ & $0.103[0.106]$ & 0.221 \\
\hline cannot say & $0.138[0.059]^{* *}$ & $0.180[0.102]^{*}$ & $0.127[0.101]$ & 0.310 \\
\hline missing info. & $0.050[0.076]$ & $0.136[0.123]$ & $0.087[0.121]$ & 0.218 \\
\hline \multicolumn{5}{|l|}{ Father smoking } \\
\hline non-smoker & $-0.159[0.033]^{* * *}$ & $-0.226[0.050]^{* * *}$ & $-0.217[0.051]^{* * *}$ & 0.426 \\
\hline missing info. & $-0.167[0.109]$ & $-0.194[0.169]$ & $-0.199[0.167]$ & 0.076 \\
\hline \multicolumn{5}{|l|}{ Mother smoking } \\
\hline non-smoker & $-0.073[0.040]^{*}$ & $-0.158[0.059]^{* * *}$ & $-0.147[0.060]^{* *}$ & 0.312 \\
\hline missing info. & $-0.155[0.095]$ & $-0.286[0.114]^{* *}$ & $-0.253[0.123]^{* *}$ & 0.131 \\
\hline \multicolumn{5}{|c|}{ Other smokers in the family } \\
\hline no & $-0.108[0.046]^{* *}$ & $-0.202[0.067]^{* * *}$ & $-0.182[0.070]^{* * *}$ & 0.785 \\
\hline missing info. & $0.088[0.085]$ & $0.092[0.147]$ & $0.109[0.152]$ & 0.103 \\
\hline \multicolumn{5}{|l|}{ Siblings } \\
\hline no. elder siblings & $0.026[0.017]$ & $0.037[0.028]$ & $0.036[0.028]$ & 0.979 \\
\hline no. younger siblings & $0.020[0.021]$ & $0.045[0.036]$ & $0.040[0.036]$ & 0.523 \\
\hline \multicolumn{5}{|l|}{ School intake } \\
\hline$\%$ father's social class I & $-0.005[0.001]^{* * *}$ & $-0.007[0.002]^{* *}$ & $-0.006[0.002]^{* *}$ & 11.911 \\
\hline missing info. & $0.022[0.099]$ & $-0.089[0.140]^{* *}$ & $-0.051[0.146]$ & 0.153 \\
\hline$\sigma^{2}$ & & $1.185[0.090]^{* * *}$ & $1.096[0.043]^{* * *}$ & \\
\hline$\rho$ & & & $0.192[0.094]^{* *}$ & \\
\hline N. obs. & 1754 & 1754 & 1754 & \\
\hline Wald test regression ${ }^{(a)}$ & $212.14[0.00]$ & $182.43[0.00]$ & $507.73[0.00]$ & \\
\hline \multicolumn{5}{|l|}{ Wald test parents' $\mathrm{edu}^{(b)}$} \\
\hline smoking equation & & & $9.56[0.48]$ & \\
\hline HE equation & & & $58.36[0.00]$ & \\
\hline
\end{tabular}

Note. Robust standard errors in brackets. The dependent variable is the number of cigarettes smoked daily by current smokers at age 30. All explanatory variables, except HE, refer to age 10. The reference individual has less than HE at age 30, most friends smoking at age 10, a mother very interested in her education, father and mother who smoked and other smokers in her family at age 10. The model also controls for region of residence at age 10. ${ }^{(a)}$ Wald test for the significance of all regressors but the constant (p-value in brackets). ${ }^{(b)}$ Wald test for the exclusion of parents' education from the smoking and the HE equations ( $\mathrm{p}$-value in brackets) performed in the ES Poisson model including parents' education in both equations.

${ }^{* * *}$ significant at $1 \% ;{ }^{* *}$ significant at $5 \%$; significant at $10 \%$. 
Table 5. Effect of explanatory variables on the IRR of smoking - Men

\begin{tabular}{|c|c|c|c|c|}
\hline \multirow[b]{2}{*}{ Variable } & \multirow{2}{*}{$\begin{array}{c}\text { Poisson } \\
\Delta \text { IRR }[\mathrm{RSE}]\end{array}$} & \multirow{2}{*}{$\begin{array}{l}\text { Poisson }+ \text { unobs. Het. } \\
\Delta \text { IRR }[\text { RSE }]\end{array}$} & \multirow{2}{*}{$\begin{array}{r}\text { ES Poisson } \\
\Delta \text { IRR [RSE] }\end{array}$} & \multirow[t]{2}{*}{ mear } \\
\hline & & & & \\
\hline \multicolumn{5}{|l|}{ Education at age 30} \\
\hline $\mathrm{HE}$ & $-0.248[0.036]^{* * *}$ & $-0.389[0.048]^{* * *}$ & $-0.607[0.093]^{* * *}$ & 0.232 \\
\hline \multicolumn{5}{|l|}{ Parents } \\
\hline no mother & $0.254[0.324]$ & $0.436[0.691]$ & $0.351[0.643]$ & 0.006 \\
\hline no father & $0.181[0.118]$ & $0.394[0.246]$ & $0.366[0.239]$ & 0.058 \\
\hline \multicolumn{5}{|l|}{ Friends smoke } \\
\hline some of them & $-0.342[0.099]^{* * *}$ & $-0.426[0.095]^{* * *}$ & $-0.425[0.096]^{* * *}$ & 0.346 \\
\hline none of them & $-0.365[0.095]^{* * *}$ & $-0.445[0.091]^{* * *}$ & $-0.439[0.093]^{* * *}$ & 0.487 \\
\hline missing info. & $-0.348[0.104]^{* * *}$ & $-0.449[0.104]^{* * *}$ & $-0.443[0.106]^{* * *}$ & 0.156 \\
\hline \multicolumn{5}{|c|}{ Father interested in child's education } \\
\hline little interest & $0.121[0.047]^{* *}$ & $0.214[0.086]^{*}$ & $0.159[0.087]^{*}$ & 0.310 \\
\hline cannot say & $0.004[0.059]$ & $0.114[0.107]$ & $0.074[0.104]$ & 0.115 \\
\hline missing info. & $0.116[0.080]$ & $0.298[0.152]^{*}$ & $0.253[0.149]^{*}$ & 0.161 \\
\hline \multicolumn{5}{|l|}{ Father smoking } \\
\hline non-smoker & $-0.076[0.034]^{* *}$ & $-0.146[0.053]^{*}$ & $-0.109[0.059]^{*}$ & 0.497 \\
\hline missing info. & $-0.311[0.120]^{* * *}$ & $-0.530[0.139]^{* * *}$ & $-0.489[0.150]^{* * *}$ & 0.088 \\
\hline \multicolumn{5}{|l|}{ Mother smoking } \\
\hline non-smoker & $-0.113[0.033]^{* * *}$ & $-0.148[0.055]^{* * *}$ & $-0.136[0.056]^{* *}$ & 0.345 \\
\hline missing info. & $-0.163[0.087]^{*}$ & $-0.227[0.141]^{*}$ & $-0.234[0.138]^{*}$ & 0.125 \\
\hline \multicolumn{5}{|c|}{ Other smokers in the family } \\
\hline no & $0.058[0.059]$ & $0.014[0.091]$ & $0.026[0.093]$ & 0.794 \\
\hline missing info. & $0.223[0.117]^{*}$ & $0.337[0.185]^{*}$ & $0.333[0.183]^{*}$ & 0.104 \\
\hline \multicolumn{5}{|l|}{ Ethnicity } \\
\hline non-European & $-0.397[0.079]^{* * *}$ & $-0.465[0.111]^{* * *}$ & $-0.461[0.112]^{* * *}$ & 0.026 \\
\hline missing info. & $0.389[0.259]$ & $0.826[0.577]$ & $0.751[0.548]$ & 0.070 \\
\hline \multicolumn{5}{|l|}{ Siblings } \\
\hline no. elder siblings & $0.007[0.018]$ & $0.017[0.031]$ & $0.006[0.032]$ & 0.942 \\
\hline no. younger siblings & $0.030[0.022]$ & $0.048[0.037]$ & $0.038[0.038]$ & 0.521 \\
\hline$\sigma^{2}$ & & $1.273[0.093]^{* * *}$ & $1.143[0.045]^{* * *}$ & \\
\hline$\rho$ & & & $0.256[0.113]^{* *}$ & \\
\hline N. obs. & 1980 & 1980 & 1980 & \\
\hline Wald test $^{(a)}$ & $134.79[0.00]$ & $133.14[0.00]$ & $435.58[0.00]$ & \\
\hline \multicolumn{5}{|c|}{ Wald test parents' edu. ${ }^{(a)}$} \\
\hline smoking equation & & & $8.66[0.57]$ & \\
\hline HE equation & & & $79.18[0.00]$ & \\
\hline
\end{tabular}

Note. Robust standard errors in brackets. The dependent variable is the number of cigarettes smoked daily by current smokers at age 30. All explanatory variables, except HE, refer to age 10. The reference individual is of European ethnicity, has less than $\mathrm{HE}$ at age 30, most friends smoking at age 10, a father very interested in his education, father and mother who smoked and other smokers in his family at age 10 . ${ }^{(a)}$ Wald test for the significance of all regressors but the constant (p-value in brackets). ${ }^{(b)}$ Wald test for the exclusion of parents' education from the smoking and the HE equations ( $p$-value in brackets) performed in the ES Poisson model including parents' education in both equations.

*** significant at $1 \% ;{ }^{* *}$ significant at $5 \% ;{ }^{*}$ significant at $10 \%$. 
Figure 1. Number of cigarettes smoked daily (current smokers)

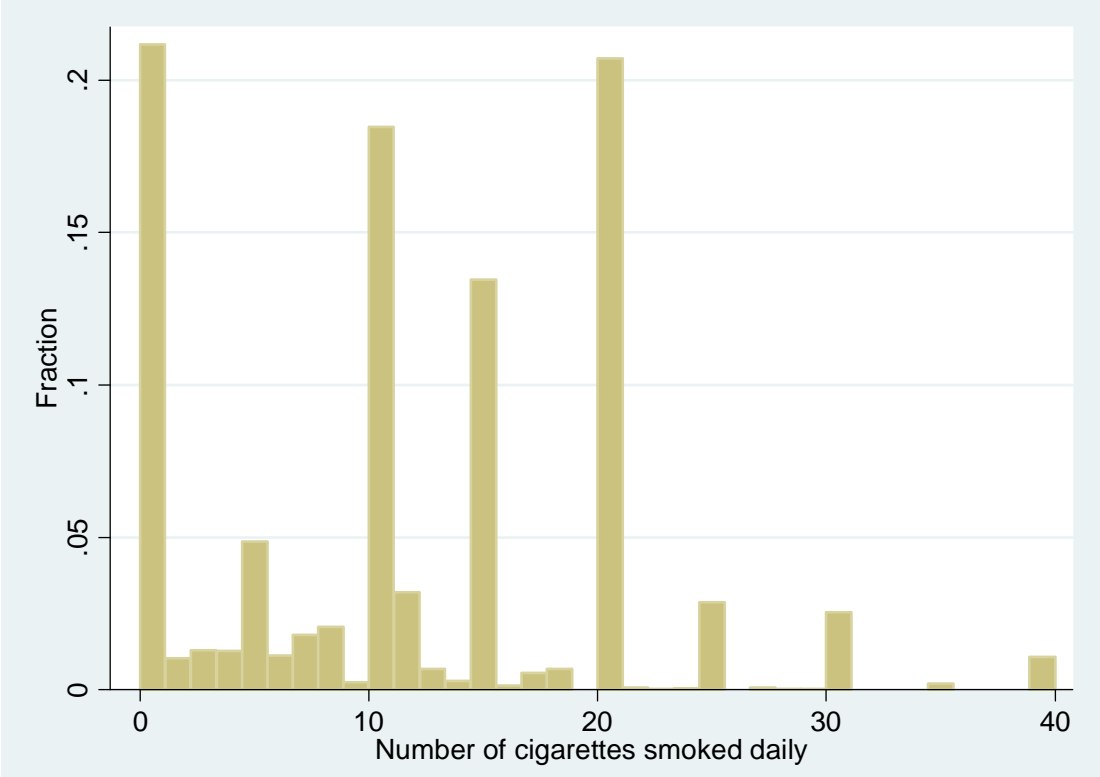

Note. This figure shows the distribution of the number of cigarettes smoked daily by current smokers in the 30-year follow-up survey of the BCS70. 


\section{Appendix}

Table 6. Probability of obtaining HE by age 30 (Switching Probit model)

\begin{tabular}{|c|c|c|}
\hline & Women & Men \\
\hline Variable & ME. [RSE] & ME [RSE] \\
\hline \multicolumn{3}{|l|}{ Parents } \\
\hline no mother & $-0.074[0.090]$ & $-0.105[0.086]$ \\
\hline no father & $-0.087[0.063]$ & $0.061[0.054]$ \\
\hline \multicolumn{3}{|l|}{ Friends smoke } \\
\hline some of them & $0.132[0.126]$ & \\
\hline none of them & $0.178[0.104]^{*}$ & \\
\hline missing info. & $0.117[0.146]$ & \\
\hline \multicolumn{3}{|c|}{ Mother interested in child's education } \\
\hline little interest & $-0.114[0.028]^{* * *}$ & \\
\hline cannot say & $-0.056[0.029]^{*}$ & \\
\hline missing info. & $-0.081[0.041]^{* *}$ & \\
\hline \multicolumn{3}{|l|}{ Father smoking } \\
\hline non-smoker & & $0.061[0.023]^{* * *}$ \\
\hline missing info. & & $0.139[0.089]$ \\
\hline \multicolumn{3}{|l|}{ Mother smoking } \\
\hline non-smoker & $0.003[0.025]$ & \\
\hline missing info. & $0.221[0.101]^{* *}$ & \\
\hline \multicolumn{3}{|c|}{ Other smokers in the family } \\
\hline no & & $0.111[0.032]^{* * *}$ \\
\hline missing info. & & $0.119[0.078]$ \\
\hline \multicolumn{3}{|l|}{ Mother's education } \\
\hline O-level & $0.033[0.033]$ & $0.034[0.029]$ \\
\hline A-level & $0.256[0.070]^{* * *}$ & $-0.071[0.044]$ \\
\hline Professional & $0.180[0.067]^{* * *}$ & $0.154[0.066]^{* *}$ \\
\hline Degree & $0.385[0.104]^{* * *}$ & $0.080[0.076]$ \\
\hline missing info. & $-0.042[0.047]$ & $-0.026[0.039]$ \\
\hline \multicolumn{3}{|l|}{ Father's education } \\
\hline O-level & $-0.015[0.035]$ & $0.036[0.033]$ \\
\hline A-level & $0.003[0.045]$ & $0.114[0.045]^{* *}$ \\
\hline Professional & $0.144[0.085]^{*}$ & $0.082[0.069]$ \\
\hline Degree & $0.171[0.062]^{* * *}$ & $0.277[0.049]^{* * *}$ \\
\hline missing info. & $-0.092[0.045]^{* *}$ & $0.011[0.048]$ \\
\hline$B A S$ score & $0.006[0.001]^{* * *}$ & $0.008[0.002]^{* * *}$ \\
\hline \multicolumn{3}{|l|}{ Siblings } \\
\hline no. elder siblings & $0.010[0.011]$ & $-0.018[0.012]$ \\
\hline no. younger siblings & $-0.021[0.017]$ & $-0.008[0.014]$ \\
\hline N. obs. & 1754 & 1980 \\
\hline
\end{tabular}

Note. This table reports marginal effects (ME) on the probability of acquiring HE by age 30 estimated using the ES Poisson model. Robust standard errors are reported in brackets. All explanatory variables refer to age 10. The female reference individual has both parents, most friends smoking, a mother who smokes, is very interested in her daughter's education and has less than O-level education, and a father with less than O-level education. The model for females also includes controls for ethnic group, social class, and days of absence from school. The male reference individual has both parents, a father who smokes and has less than O-level education, a mother with less than O-level education, and lives in a family where other members, different from the parents, smoke. The model for males also includes house property. ${ }^{* * *}$ significant at $1 \% ;{ }^{* *}$ significant at $5 \% ;{ }^{*}$ significant at $10 \%$. 


\section{References}

Adams, S., 2002. Educational attainment and health: Evidence from a sample of older adults. Education Economics 10, 97-109.

Arendt, J., 2005. Does education cause better health? A panel data analysis using school reforms for identification. Economics of Education Review 24, 149-160.

Bantle, C., Haisken-DeNew, J., 2002. Smoke signals: The intergenerational transmission of smoking behavior, DIW Discussion Papers no. 277.

Becker, G., Mulligan, C., 1997. The endogenous determination of time preference. Journal of Political Economy 112, 729-758.

Berger, M., Leigh, J., 1989. Schooling, self-selection, and health. Journal of Human Resources 24, 433-455.

Blow, L., Leicester, A., Windmeijer, F., 2005. Parental income and children's smoking behaviour: Evidence from the British household panel survey, IFS Working Papers, W05/10.

Blundell, R., Dearden, L., Goodman, A., Reed, H., 2000. Policy feature. the returns to higher education in Britain: Evidence from a British cohort. Economic Journal 110, 82-100.

Bratti, M., Naylor, R., Smith, J., 2005. Variations in the wage returns to a first degree: Evidence from the British cohort study 1970, IZA DP No. 1631.

Bynner, J., Butler, N., Ferri, E., Shepherd, P., Smith, K., 2002. The design and conduct of the 1999-2000 surveys of the national child development study and the 1970 British cohort study, CLS Cohort Studies Working Paper 1. London: Centre for Longitudinal Studies. 
Chandola, H. J., T, Bartley, M., 2004. Socio-demographic predictors of quitting smoking: How important are household factors? Addiction 90, 770777.

Chandola, T., Clarke, P., Morris, J., Blane, D., 2006. Pathways between education and health: A causal modelling approach. Journal of the Royal Statistical Society, Series A (Forthcoming).

Chevalier, A., 2004. Parental education and child's education: A natural experiment, IZA DP No. 1153.

Chevalier, A., Lanot, G., 2002. The relative effect of family characteristics and financial situation on educational achievement. Education Economics $10,165-182$.

Clark, A., Etilé, F., 2002. Do health changes affect smoking? Evidence from British panel data. Journal of Health Economics 21, 533-562.

Cragg, J., 1971. Some statistical models for limited dependent variables with application to the demand for durable goods. Econometrica 39, 829-844.

De Walque, D., 2004. Education, information, and smoking decisions: Evidence from smoking histories, 1940-2000, World Bank Policy Research Papers No. 3362.

Elliot, M. D., CD, Pearson, L., 1979. British Ability Scales, Manual 4: Tables of Abilities and Norms, Windsor: NFER.

Emery, S., White, M., Pierce, J., 2001. Does cigarette price influence adolescent experimentation? Journal of Health Economics 20, 261-270.

Ermisch, J., Francesconi, M., 2001. Family matters: Impacts of family background on educational attainments. Economica 68, 137-156.

Farrell, P., Fuchs, V., 1982. Schooling and health: The cigarette connection. Journal of Health Economics 1, 217-230. 
Fersterer, J., Winter-Ebmer, R., 2003. Smoking, discount rates, and returns to education. Economics of Education Review 22, 561-566.

Forster, M., Jones, A., 2003. Corrigendum: The role of tobacco taxes in starting and quitting smoking: Duration analysis of british data. Journal of the Royal Statistical Society, Series A 166, 441-442.

Fuchs, V., 1982. Time preference and health: An explanatory study, in: Fuchs, V. (Ed.), Economic Aspects of Health, University of Chicago Press, pp. $93-120$.

Grossman, M., 1972. On the concept of health capital and the demand for health. Journal of Political Economy 80, 223-255.

Grossman, M., 2005. Education and nonmarket outcomes, NBER Working Papers No. 11582.

Kenkel, D., 1991. Health behavior, health knowledge, and schooling. Journal of Political Economy 99, 287-305.

Kenkel, D., Terza, J., 2001. The effect of physician advice on alcohol consumption: Count regression with an endogenous treatment effect. Journal of Applied Econometrics 16, 165-184.

Labeaga, J., 1999. A double-hurdle rational addiction model with heterogeneity: Estimating the demand for tobacco. Journal of Econometrics 93, 49-72.

Lleras-Muney, A., 2005. The relationship between education and adult mortality in the United States. Review of Economic Studies 72, 189-221.

Miranda, A., Rabe-Hesketh, S., 2005. Maximum likelihood estimation of endogenous switching and sample selection models for binary, ordinal, and count variables. Stata Journal (Forthcoming). 
Nerín, I., Guillén, D., Mas, A., Crucelaegui, A., 2004. Evaluation of the influence of medical education on the smoking attitudes of future doctors. Arch Bronconeumol 40, 341-347.

Office for National Statistics, 1999. Tracking People: A guide to longitudinal social sources, London: Office for Statistics.

Powell, L., Tauras, J., Ross, H., 2005. The importance of peer effects, cigarette prices and tobacco control policies for youth smoking behavior. Journal of Health Economics 24, 950-968.

Rabe-Hesketh, S., Skrondal, A., 2002. Reliable estimation of generalized linear mixed models using adaptive quadrature. The Stata Journal 2, 1-21.

Rosenzweig, M., Schultz, T., 1983. Estimating a household production function: Heterogeneity, the demand for health inputs, and their effects on birth weight. Journal of Political Economy 91, 723-746.

Ross, C., Mirowsky, J., 1999. Refining the association between education and health: The effects of quantity, credential and selectivity. Demography 36, 445-460.

Sander, W., 1995a. Schooling and quitting smoking. Review of Economics and Statistics 92, 344-348.

Sander, W., 1995b. Schooling and smoking. Economics of Education Review $14,23-33$.

Sander, W., 1998. The effects of schooling and cognitive ability on smoking and marijuana use by young adults. Economics of Education Review 17, $317-324$.

Terza, J., 1998. Estimating count data models with endogenous switching: Sample selection and endogenous treatment effects. Journal of Econometrics $84,129-154$. 
Winkelmann, R., 1998. Count data models with selectivity. Econometric Reviews $17,339-359$.

Wolfe, B., Haveman, R., 2003. Social and nonmarket benefits from education in an advanced economy, in: Kodrzycki, Y. (Ed.), Education in the twentyfirst century: Meeting the challenges of a changing world, no. no. 47 in Conference Series, Boston: Federal Reserve Bank of Boston, pp. 97-131. 